\title{
Three-Dimensional Modeling of Concrete Reinforced with Randomly Distributed Fiber
}

\author{
Sahar Y. Ghanem \\ Eastern Kentucky University \\ 521 Lancaster Ave., 307 Whalin Complex \\ Richmond, KY 40475 \\ Sahar.ghanem@eku.edu
}

\begin{abstract}
Fibers are used in concrete structures to improve its behavior under load. The addition of fibers in concrete matrix increases the difficulty to study the mixture properties as fibers are randomly distributed inside concrete. The ability of fiber to randomly dispersed is very important in the material micro level and provide a crack arrest mechanism to improve the mechanical properties.

The objective of this paper is to provide an algorithm that accounts for fiber randomness in angle and location in the microstructure level of the material. This algorithm can be then used in Finite Element (FE) to investigate the Fiber Reinforced Concrete (FRC) under flexural loading. The numerical simulations of the specimen under flexural loading agree well with test observations, which reveal that the algorithm can simulate the material microstructure level properties and finite-element analytical approach can give reliable predictions.
\end{abstract}

Keywords: Fiber Reinforced Concrete; FRC; Algorithm; Random fibers; Finite element; flexural load; ANSYS

\section{Introduction}

Fiber-reinforced concrete (FRC) is a material made of cements, water, fine and coarse aggregate, with added discontinuous fibers. [1]. Fibers are added to concrete to improve its properties, and various types of fibers are used for this purpose: steel fiber, glass fiber, natural fiber and synthetic fiber [2].

It has been proved that steel fibers improve concrete tensile and flexural strength [3], as well as the electric, magnetic and heat properties. $[4,5,6]$. Similar to steel fiber, Glass fibers improve concrete [7], while Synthetic fibers prevent plastic shrinkage cracks in fresh concrete [8]. Adding fibers to concrete has much greater effect on the flexural properties than on either the compressive or tensile strength [9].

Although the addition of fibers in concrete matrix increases the difficulty to study the mixture properties and predict the behavior of the new mixture, experimental research showed that the primary benefit of fibers in the concrete matrix is the ability of the randomly dispersed and provide a crack arrest mechanism and enhance cracking performance. [10]. Therefore, randomness of fiber is one of the most important property to consider when modeling FRC.

Numerical modeling is a useful tool to represent the relationship between the microstructure

And the mechanical or properties of materials. Finite Element (FE) modeling has been previously used to simulate the behavior of FRC, but fibers are modeled as part of the concrete material [11, 12]. Such models do not present the randomness of fiber.

The objective of this paper is to provide an algorithm that accounts for fiber randomness in angle and location in the microstructure level of the material. The algorithm will then be used in Finite Element (FE) modeling. Since fibers have a greater effect on the concrete flexural properties than other properties, the algorithm and three-dimensional finite element model (3-D FEM) are used to calculate the flexural strength.

\section{Algorithm to Generate Random Fibers}

Fibers are distributed randomly in FRC regardless the material used for fibers. It is necessary to create an algorithm to generate fibers randomly inside the certain domain; in this case concrete beam; to capture an accurate material property for 
the concrete mixture. The resultant interaction between concrete and fiber in the numerical modeling is highly affected by how accurate the model can represent a random angle and location for the fibers.

MATLAB software is used to build the algorithm. In this algorithm, fibers are considered straight with circular cross section and with specific constant length, which in three dimensions (3D) makes one fiber as cylinder.

As shown in Fig. 1, cylinder in $3 \mathrm{D}$ can described by start point $\mathrm{X}_{1}\left(x_{1}, y_{1}, z_{1}\right)$ and end point $\mathrm{X}_{2}\left(x_{2}, y_{2}, z_{2}\right)$, radius $\left(r_{f}\right)$, length $\left(l_{f}\right)$, and two Euler angles $\left(\varphi_{f}\right)$ and $\left(\theta_{f}\right)$ with positive $\mathrm{x}$ and $\mathrm{z}$ axes respectively.

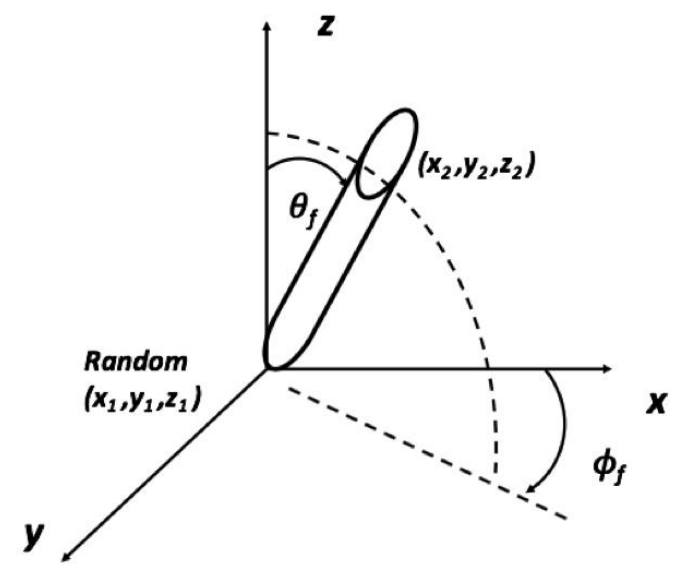

Fig. 1: Coordinate system for random fiber.

\subsection{Generate One Fiber}

The following steps are followed to generate one fiber randomly:

1. Generate the starting location of the fiber $\left(\mathrm{X}_{1}\right)$ randomly. In this study, Mersenne Twister (MT) algorithm is used is used to generate pseudo-random number list, this algorithm developed by M. Matsumoto and T. Nishimura [13]. The generated point must be within the concrete domain.

2. Generate Euler angles $\left(\varphi_{f}\right)$ and $\left(\theta_{f}\right)$ randomly MT algorithm that used to generate the fiber starting point $\left(\mathrm{X}_{1}\right)$.

3. Calculate the second point $\left(\mathrm{X}_{2}\right)$. Where $\mathrm{X}_{2}$ can be calculated using the following equation:

$$
\begin{aligned}
& x_{2}=x_{1}+l_{f}\left(\sin \theta_{f}\right)\left(\cos \varphi_{f}\right) \\
& y_{2}=y_{1}+l_{f}\left(\sin \theta_{f}\right)\left(\sin \varphi_{f}\right) \\
& z_{2}=z_{1}+l_{f}\left(\cos \theta_{f}\right)
\end{aligned}
$$

4. Check if the fiber second end $X_{2}$ is within the domain. If $X_{2}$ is outside the domain, step 2 will be repeated up to $10^{6}$ trials. if after that the algorithm can't find a second point inside the domain, a new $\mathrm{X}_{1}$ will be generated as in step 1

\subsection{Number of Fibers}

The steps discussed is used to generate one fiber. But the algorithm will generate several fibers to satisfy the required fiber volume fraction in the specimens $\left(V_{f}\right)$, where the number of fibers required $\left(n_{f}\right)$ can be calculated using Equation 4. The number of fibers is rounded up to the nearest integer.

$$
n_{f}=V_{f} \frac{\text { Volume }_{d}}{\text { Volume }_{f}}
$$


Where Volume $_{d}$ is the volume of the domain. In this study the domain is a beam. Therefore, Volume can $_{\text {be }}$ calculated using Equation 5:

$$
\text { Volume }_{d}=d_{b} \times b_{b} \times L
$$

Where $d_{b}, b_{b}$ and $L$ are the beam depth, width and length respectively.

On the other hand, Volume $_{f}$ is the volume of one fiber and can be calculated using Equation 6 as the following:

$$
\text { Volume }_{f}=\pi \times r_{f}^{2} \times l_{f}
$$

\subsection{Intersection}

When mixing concrete with fibers, fibers do not intersect. It is important to model the mixture with insuring that fibers don't intersects in the domain. The criteria followed in this study to satisfy this condition is to generate a fiber with a minimum distance with all other fiber equal to twice the fiber radius $\left(2 r_{f}\right)$. For each generated fiber using steps 1 to 4 , the fiber minimum distance is calculated between the newly generated fiber and all previously generated fibers. If the condition is not satisfied, the newly generated fiber is rejected. The algorithm implemented here is the one used by Sunday [14]. The first step is to get the closest points for the infinite lines that they lie on. If they are in the range of the fibers segment, then they are also given closest points. But if they lie outside the range of either, determine new points over the ranges of interest.

\subsection{Input and Flow Chart}

All required rules are put together in one algorithm. The inputs for the created algorithm are related to the beam and fiber dimension, which are usually predetermined. The following are the input for the algorithm:

- Fiber volume fraction $\left(V_{f}\right)$

- Fiber dimensions: radius $\left(r_{f}\right)$, length $\left(l_{f}\right)$

- Dimensions of specimens: $d_{b}, b_{b}$ and $L$ are the beam depth, width and length respectively.

Fig. 2 shows a flow chart that summarizes the algorithm. After the algorithm generates the required number of fibers, the program stops, and data saved in output file. The output file includes the starting and ending points $\left(X_{1}, X_{2}\right)$ for all random fibers. This data will be transferred to Finite Element program to generate the geometry of the fibers. 


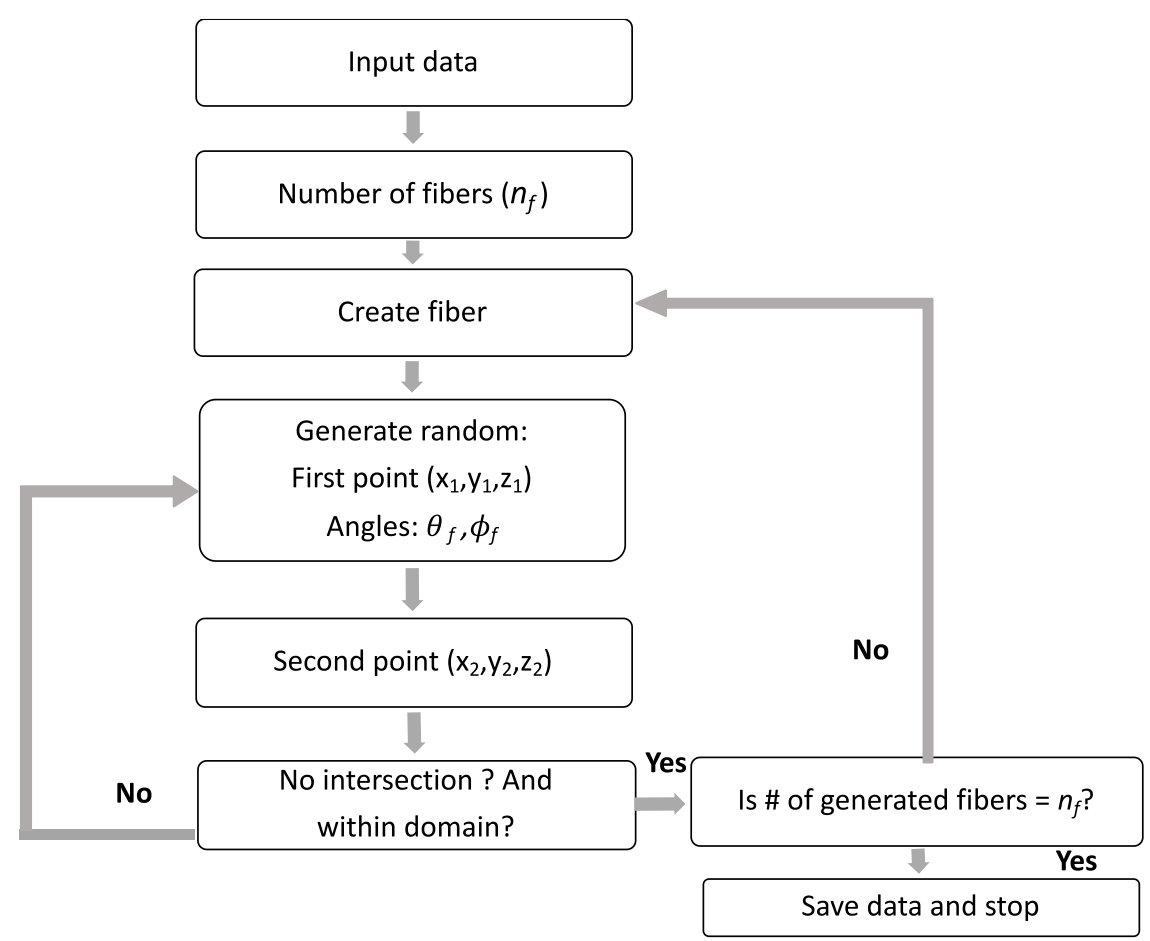

Fig. 2: Flowchart of Algorithm.

\section{Algorithm Verification}

To verify that the algorithm will generate a random fibers inside domain that represents the real randomness in FRC mixture, the results of the algorithm is compared to experimental data in literature. Stähli, et al. has an experimental research to study steel fibers orientation and distribution in concrete [15]. The study used CT-Scan to reconstruct a 3-D of the fiber distribution inside concrete beam. The data in the study are used in the proposed algorithm to generate the fibers and the data is transferred to ANSYS [16] to visualize the section. The results are shown in Fig. 3. Fig. 3-a shows the 3-D reconstruction of steel fibers in FRC from CT-Scan [15], and Fig. 3-b shows steel fibers generated using the algorithm of the current study.

From the comparison, it can be seen the proposed algorithm can successfully modeled the mixture microstructure and achieved the randomness in generating fibers, an important aspect that is required to model FRC.

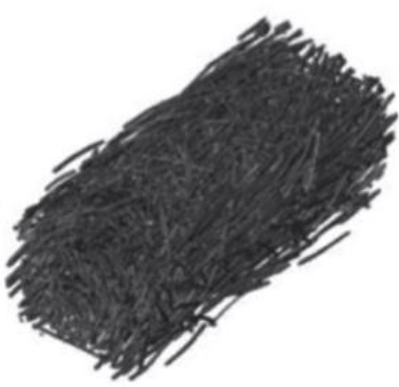

(a)

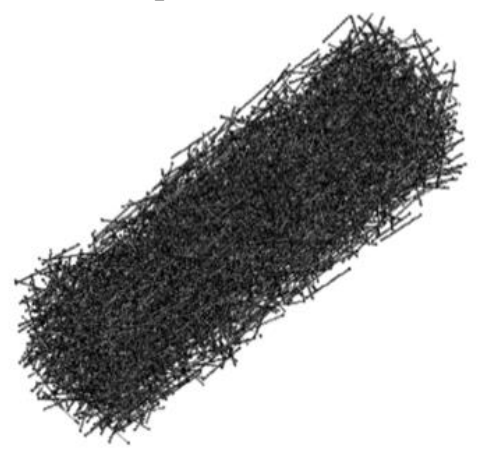

(b)

Fig. 3: (a) 3D reconstruction of steel fibers in FRC from CT-Scan (Stähli, Custer and Van Mier 2008), (b) Algorithm generation of steel fibers (Current study). 


\subsection{Flexure Behavior Testing}

This section of the study focuses on the relationship between the microstructure and the mechanical properties of the mixture. Since adding fibers to concrete has much greater effect on the flexural properties than on either the compressive or tensile strength [9]. The focus of this study is to use the proposed algorithm to model FRC flexural behavior. The flexural performance of Fiber-Reinforced Concrete (FRC) can be tested Using Beam with Third-Point Loading based on ASTM C1609 [17]. The setup of the test is shown in Fig. 4. A displacement is applied at third distance and load displacement are monitored at the middle of the concrete beam.

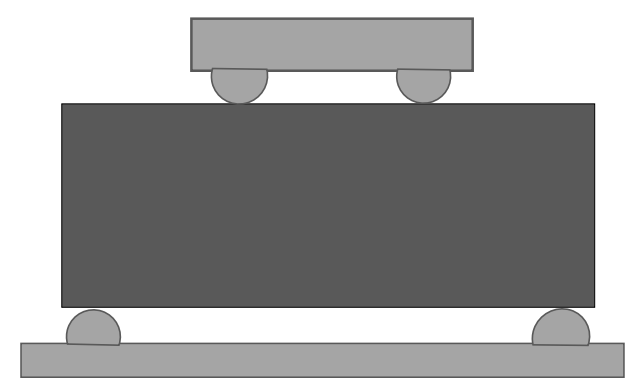

Fig. 4: Flexural test setup for beam.

The target in here is to find the beam flexural strength or modulus of rupture $(f)$ using equation 7 .

$$
f=\frac{P L_{s}}{b d^{2}}
$$

$f:$ the strength (modulus of rupture)

$P$ : the load

$L_{s}:$ the span length

$b$ : the average width of the specimen at the fracture

$d$ : the average depth of the specimen at the fracture

\subsection{FRC Finite Element Modeling}

Commercial FE software ANSYS APDL [16] is used to carry out the FE analysis using the appropriate elements and models for materials. Since this algorithm can be used with any fiber materials (Steel, Carbon, etc), only materials used in this study will be discussed.

\subsubsection{Element Types}

Concrete is modeled using SOLID 65 element. This element is ANSYS concrete element with built-in cracking and crushing capabilities. All fibers are modeled as LINK 180, The element is a uniaxial tension-compression element with Tension-only (cable) and compression-only (gap) options [16], which makes it suitable for different fibers material modeling. Any loading steel plates used in the study, will be modeled as brick element SOLID 185.

\subsubsection{Material Properties}

Concrete material is modeled using a nonlinear uniaxial stress strain. The model proposed by Kent and Park [18] is used to model the concrete behavior in compression. The concrete maximum tensile stress $\left(f_{t}\right)$ is calculated based on ACI code [19] as:

$$
f_{t}=0.56 \sqrt{f_{c}^{\prime}}
$$


Where $f_{c}^{\prime}$ is the unconfined concrete maximum compressive strength.

Willam and Warnke (1975) model [20] is used to define the failure of the concrete.

Any steel part will be modeled as elastic-perfectly plastic material. The yield stress $\left(f_{y}\right)$, elastic modulus $\left(E_{s}\right)$ and Poisson's ratio $\left(v_{s}\right)$ values depend on each individual study. Finally, composite polymers are modeled as linear elastic material.

\subsubsection{Mesh and Loading}

Due to symmetry, a quarter of the test is modeled, and the load is applied as an equivalent displacement at top of the columns. Small mesh size is used to use shared nodes between concrete and fibers. The Full Newton-Raphson method is adopted to solve the set of nonlinear equations, with a sufficiently number of solution sub-steps during the loading process.

\subsection{Validation of Model and discussion}

The algorithm and Finite Element Model are validated by comparing the results of the model with experimental studies in literature. Three beams are chosen from three different studies: M2 [21], N4 [22], and 4PBT-small beams (Macrofiber) [23]. These beams are selected carefully to include a wider choices of fiber material and size, concrete strength, and beam size. The experimental and FE results are listed in Table 1. The results percentage error (\% Error) is calculated using equation 9.

$$
\% \text { Error }=\frac{\left|f_{\text {exp }}-f_{F E}\right|}{f_{\text {exp }}} \times 100 \%
$$

There is a good agreement between the experimental and FE results. The \% Error ranged between 0.78 and 4.78. Based on that, the algorithm along with the finite element model can predict the flexural behavior of FRC beam with high accuracy.

Table 1: Comparison between experimental and Finite Element Results.

\begin{tabular}{|l|l|l|c|}
\hline Specimen & $\begin{array}{l}f_{\text {exp }} \\
\text { (MPa) }\end{array}$ & $\begin{array}{l}f_{F E} \\
\text { (MPa) }\end{array}$ & Error \% \\
\hline M2 [21] & 5.23 & 5.48 & 4.78 \\
\hline N4 [22] & 6.40 & 6.45 & 0.78 \\
\hline 4PBT-small beams (Macrofiber) [23] & 3.8 & 3.66 & 3.68 \\
\hline
\end{tabular}

\section{Summary and Conclusions}

This research presents an algorithm that accounts for fiber randomness in angle and location in the microstructure level of the material. This algorithm can be then used in Finite Element (FE) to investigate the Fiber Reinforced Concrete (FRC) under flexural loading.

It is necessary to create an algorithm to generate fibers randomly inside the certain domain; in this case concrete beam; to capture an accurate material property for the concrete mixture. The resultant interaction between concrete and fiber in the numerical modeling is highly affected by how accurate the model can represent a random angle and location for the fibers. 
The algorithm generates one fiber by randomly generating the starting location $\left(\mathrm{X}_{1}\right)$ and Euler angles $\left(\varphi_{f}, \theta_{f}\right)$ of the fiber randomly using Mersenne Twister (MT) algorithm. From which the location of the fiber end $\left(\mathrm{X}_{2}\right)$ is calculated and within domain.

This process will be repeated to generate all fibers required to satisfy the targeted fiber volume fraction in the specimens $\left(V_{f}\right)$. The randomly generated fibers should not intersect with each other. This condition is applied in this study by generating fiber with a minimum distance with all other fiber equal to twice the fiber radius $\left(2 r_{f}\right)$. If the condition is not satisfied, the newly generated fiber is rejected.

The required inputs for the proposed algorithm are: Fiber volume fraction $\left(V_{f}\right)$, fiber radius $\left(r_{f}\right)$, fiber length $\left(l_{f}\right)$, specimens depth $\left(d_{b}\right)$, specimens width $\left(b_{b}\right)$, and specimens length $(L)$. The output data are the starting and ending points $\left(\mathrm{X}_{1}, \mathrm{X}_{2}\right)$ for all random fibers, where this file can be read by the Finite Element program ANSYS.

Comparing the algorithm generated fibers with a reconstructed 3-D picture of the fiber distribution inside concrete beam using CT-Scan, the proposed algorithm can successfully achieve the randomness in generating fibers, an important aspect that is required to model FRC.

The flexural performance of Fiber-Reinforced Concrete (FRC) is tested using beam with third-point loading test setup. The most appropriate elements type and material properties are used.

The algorithm and Finite Element Model are validated by comparing the results of the model with experimental studies in literature. Three beams are chosen from three different studies representing a wide choices of fiber material and size, concrete strength, and beam size.

There is a good agreement between the experimental and FE results, and the \% Error ranged between 0.78 and 4.78.

The numerical simulations of the specimen under flexural loading agree well with test observations, which reveal that the algorithm and finite-element analytical approach can give reliable predictions.

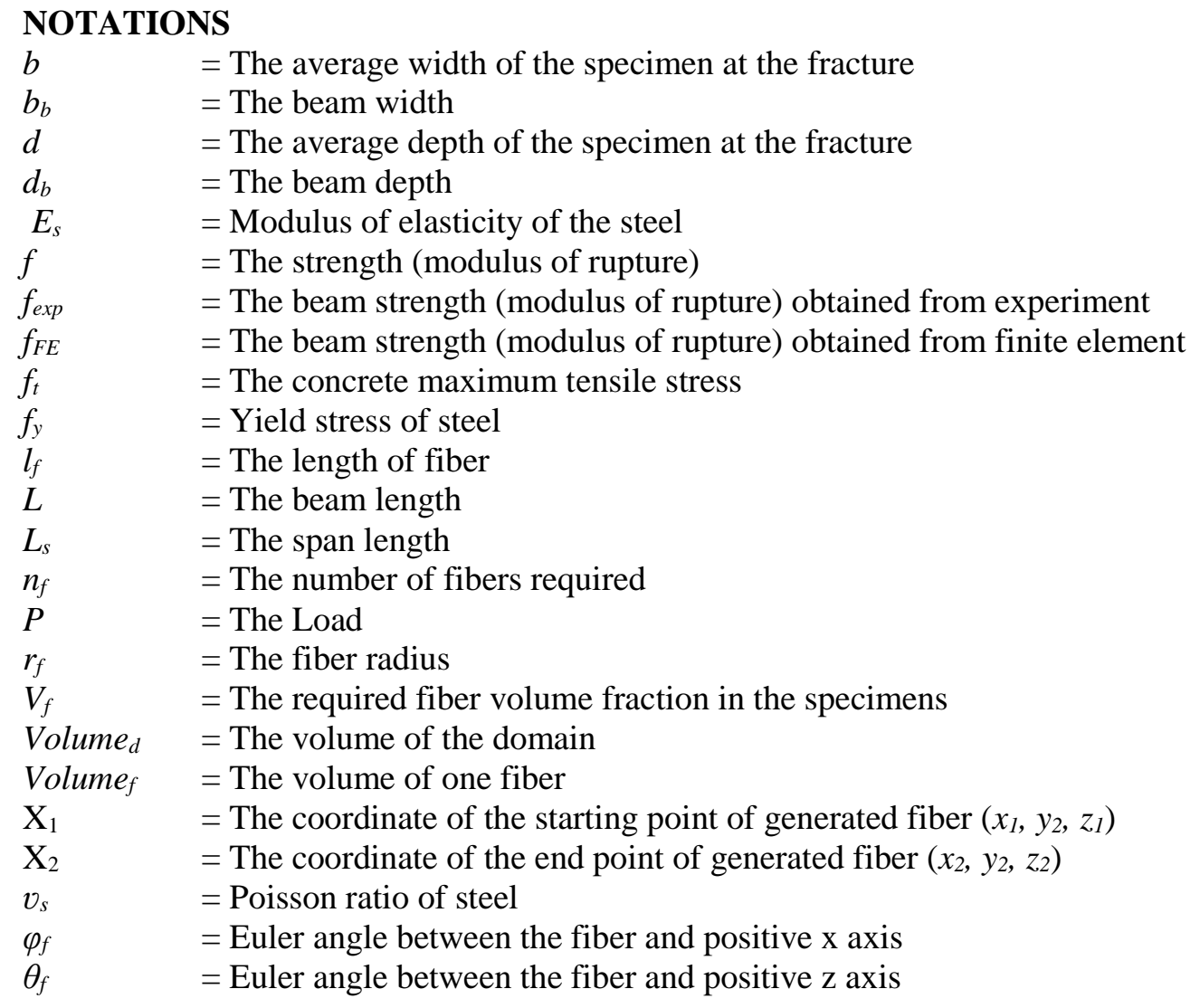




\section{References}

[1] ACI Committee 544, "Guide for Specifying, Proportioning, and Production of Fiber-Reinforced Concrete," American Concrete Institute, Farmington Hills, MI, 2008.

[2] S. Yin, R. Tuladhar, F. Shi, M. Combe, T. Collister and N. Sivakugan, "Use of macro plastic fibres in concrete: A review," Construction and Building Materials, vol. 93, p. 180-188. DOI: 10.1016/j.conbuildmat.2015.05.105, 2015.

[3] A. Beglarigale and H. Yazici , "Pull-out behavior of steel fiber embedded in flowable RPC and ordinary mortar," Construction and Building Materials, vol. 75, pp. 255-265 .https://doi.org/10.1016/j.conbuildmat.2014.11.037, 2015.

[4] P. Sukontasukkul, W. Pomchiengpin and S. Songpiriyakij, "Post-crack (or post-peak) flexural response and toughness of fiber reinforced concrete after exposure to high temperature," Construction and Building Materials, vol. 24, no. 10, pp. 1967-1974, 2010.

[5] Q. Dai , Z. Wang and M. Hasan , "Investigation of induction healing effects on electrically conductive asphalt mastic and asphalt concrete beams through fracture-healing tests," Construction and Building Materials, vol. 49, pp. 729737, 2013.

[6] Al-Mattarneh, "Electromagnetic quality control of steel fiber concrete," Construction and Building Materials, vol. 73, pp. 350-356. https://doi.org/10.1016/j.conbuildmat.2014.09.101, 2014.

[7] S. Tassew and A. Lubell , "Mechanical properties of glass fiber reinforced ceramic concret," Construction and Building Materials, vol. 51, pp. 215-224, 2014.

[8] M. Cao, C. Zhang C and H. Lv, "Mechanical response and shrinkage performance of cementitious composites with a new fiber hybri," Construction and Building Materials, vol. 57, pp. 45-52, 2014.

[9] P. Song and S. Hwang, "Mechanical properties of high-strength steel fiber-reinforced concrete," Construction and Building Materials, vol. 18, p. 669-673. doi.org/10.1016/j.conbuildmat.2004.04.027, 2004.

[10] Z. Xu , H. Hao and H. Li , "Mesoscale modelling of fibre reinforced concrete material under compressive impact loading," Construction and Building Materials, vol. 26, p. 274-288, 2012.

[11] M. Islam, M. Khatun, M. Islam and S. Dola, "Finite Element Analysis of Steel Fiber Reinforced Concrete(SFRC): Validation of Experimental shear Capacities of Beams," Procedia Engineering, vol. 90, pp. 89-95 , 2014.

[12] M. Özcan, A. Bayraktar, A. Shahin, T. Haktanir and T. Türker, "Experimental and finite element analysis on the steel fiber-reinforced concrete (SFRC) beams ultimate behavior," Construction and Building Materials, vol. 23, p. 10641077, 2009.

[13] M. Matsumoto and T. Nishimura, "Mersenne twister: a 623-dimensionally equidistributed uniform pseudo-random number generator," ACM Transactions on Modeling and Computer Simulation (TOMACS), vol. 8, no. 1, pp. 3-30, 1998.

[14] D. Sunday, "Geometry Algorithms," 2012. [Online]. Available: http://geomalgorithms.com/a07_distance.html\#dist3D_Segment_to_Segment. [Accessed 11 2017].

[15] P. Stähli, R. Custer and J. Van Mier, "On flow properties, fibre distribution, fibre orientation and flexural behaviour of FRC," Materials and Structures, vol. 41, no. 1, pp. 189-196. https://doi.org/10.1617/s11527-007-9229-x, 2008.

[16] ANSYS, "Documentation for ANSYS. Version 17.2," ANSYS Inc, Canonsburg, PA, USA, 2016.

[17] ASTM, "Standard C1609/C1609M-12. 2012. Standard Test Method for Flexural Performance of Fiber-Reinforced Concrete (Using Beam With Third-Point Loading)," ASTM International, West Conshohocken, PA., 2012.

[18] D. C. Kent and R. Park, "Flexural members with confined concrete," Journal of Structures. Div., ASCE, vol. 97, no. 7, pp. 1969-1990, 1971.

[19] 3.-1. ACI, "Building Code Requirements for Reinforced Concrete," American Concrete Institute, Farmington, MI, 
USA, 2014.

[20] K. J. Willam and E. P. Warnke, "Constitutive models for the triaxial behavior of concrete," Proceedings of the International Assoc. for Bridge and Structural Engineering, vol. 19, pp. 1- 30, 1975.

[21] M. Hsiea and . T. C. Song, "Mechanical properties of polypropylene hybrid fiber-reinforced concrete," Materials Science and Engineering A, vol. 494, no. 1-2, pp. 153-157, 2008.

[22] N. Banthia and R. Gupta, "Hybrid fiber reinforced concrete (HyFRC): fiber synergy in high strength matrices," Materials and Structures, vol. 37, no. 10, p. 707-716, 2004.

[23] L. Sorelli, A. Meda and G. Plizzari, "Bending and Uniaxial Tensile Tests on Concrete Reinforced with Hybrid Steel Fibers," Journal of Materials in Civil Engineering, vol. 17, no. 5, p. 519-527, 2005. 